\section{Pandemic research: UK must coordinate}

As a former chief scientific adviser to the UK government (in the Department for Business, Innovation and Skills, 2015-16), I am concerned that the country's premier research assets in biological science are not being effectively coordinated in response to the COVID-19 pandemic. This is delaying potentially important advances that could save lives.

My own research is contributing to the development of coronavirus tests and therapeutics. This gives me insight into how well the United Kingdom's COVID-19 research is being coordinated.

The government's UK Research and Innovation organization should be applauded for rapidly freeing up more research funding. However, this and other leading UK science groups have stood back from formal coordination of the UK research effort. Instead, they are following the 'peacetime' route of allowing academics to self-assemble. This is an inadequate approach in a time of national crisis, in my view.

As we enter the second phase of the pandemic, I urge the United Kingdom to establish a leadership council for coordinating COVID-19 research. This should marshal scientists and social scientists, steer the sharing of information and resources, link disciplines and ensure that academic and commercial researchers work together.

Tim R. Dafforn University of Birmingham, UK.

t.r.dafforn@bham.ac.uk

The author declares competing financial interests

(see go.nature.com/2tyism7).

\section{Women join Italy's COVID task force}

Six women have now joined the 20 men in the Italian government's COVID-19 emergency task force, after a public appeal from leading Italian female scientists (see go.nature.com/2u4gtfj). The petitioners argued that the original imbalance could have been avoided had the committee's selection paid more attention to merit.

In Italy, the evaluation of research performance is influenced by factors that are unfavourable to women. For example, it fails to take into account time spent away from research to care for children or elderly relatives, which typically means fewer publications. Italian women carry a much heavier share of these family roles than do men; nurseries meet just $25 \%$ of potential demand and elderly people account for almost one-quarter of the population.

The welcome addition of women to the coronavirus task force is a tacit acknowledgement that all genders would score comparably on research impact if they could spend the same amount of time in the lab.

Giovanni Abramo National Research Council of Italy, Rome, Italy. giovanni.abramo@uniroma2.it

\section{Adapt lab life to social distancing}

As laboratory operations prepare to restart, researchers will have to adjust to institutional distancing restrictions (see Nature 582, 15-16;2020). Unfortunately, there's no playbook. We need to set up our environment so that a distributed scientific workforce can thrive.

There's an opportunity here to fix those parts of the research machine that are broken - including inefficiencies, redundancies and irreproducibilities. We shall need infrastructure that enables us to share data, to connect team members and to communicate asynchronously as well as synchronously. Despite a surge in software-asa-service start-ups, there is no single solution to help a lab to achieve these goals. Instead, each will have to find the right set of tools for its operation.

Imagine scientists sharing data as they are generated, recording analyses as they happen, receiving feedback from multiple sources and making measurable progress on lab projects - all in separate shifts. Imagine now that this scientific nirvana persists beyond shift-work restrictions. The new way of operating will accelerate scientific progress including towards therapeutics for COVID-19, which provoked it in the first place.

Matthew Hirschey Duke University Medical Center, Durham, North Carolina, USA. matthew.hirschey@duke.edu

\section{Squabbling impedes locust control}

Pakistan and India are facing their biggest outbreak of desert locust swarms in 25 years (see Nature 579, 330; 2020 and Nature 579, 174; 2020). Despite last year's stand-off, the neighbouring countries agreed to cooperate against this international crop pest under the umbrella of the Food and Agriculture Organization of the United Nations (see go.nature.com/2mmdkdq). However, political tension and cross-border conflicts continue to undermine control measures.

These measures merit every support, irrespective of jurisdictional boundaries. The food security of 2.5 billion people is at stake. In our view, the governments of both countries need to act immediately to correct the management flaws and cooperation loopholes that have been exposed during the locust invasion that started more than 2 months ago.

We urge governments and citizens in both countries to work together to sustainably manage this insect menace. They should develop a shared early-warning information system along their border to help prevent future outbreaks. Meanwhile, governments must maintain the necessary funds to compensate severely affected rural populations.

Muhammad Wajid Javed,

Mansoor ul Hasan University of Agriculture, Faisalabad, Pakistan. muhammadwajidjaved@ gmail.com

Muhammad Usman Sultan Qaboos University, Muscat, Oman. 